\title{
Facts and fallacies about gall stones
}

Gall stones are common in Britain and, indeed, in most developed countries. ${ }^{12}$ At least $15 \%$ of adults will have formed gall stones by the time they die, but most of these appear to be incidental findings at necropsy and so are silent in life. The prevalence of cholecystectomy is very much lower. Selecting individuals for investigation for gall-stone disease, therefore, depends partly on deciding who is most likely to have the condition, but more important on whether symptoms may plausibly be ascribed to cholelithiasis if found to be present. Mild dyspepsia, flatulence, and fat intolerance are not themselves an indication for an oral cholecystogram. ${ }^{3}$ Doubts about the wisdom of investigating a patient may be supported by the rarity of death from gall stones and the inescapable hazards of surgery.

A recent series of advertisements in the medical press has repeated the antique aphorism that the classic patient with gall stones is a fat, fair, fertile, 40 -year-old female, who is also sometimes described as flatulent. Unfortunately any clinician relying on that stereotype would not only investigate many patients unnecessarily but also miss most gall stones.

Let us look at each of the features in turn. Firstly, fat: obesity has long been thought to predispose to gall stones, and there is circumstantial supporting evidence from the analysis of bile. Conclusive proof is, however, lacking: many patients are commendably slim, and body build should not influence ideas about individuals. Fat in the diet cannot plausibly be linked to the formation of gall stones, though it may precipitate biliary colic in some patients with stones.
Next, the association with a fair complexion is plain falsehood. Not only are fair-haired persons no more prone to gall stones than the rest of the community but the highest prevalence in the world occurs in American Indians.

Though high parity has been linked with formation of gall stones, nulliparous women also have a high prevalence. For practical purposes the most important modern factor is the use of oestrogens in oral contraceptives. These agents probably double the frequency of gall-stone disease by causing a deterioration in the cholesterol saturation of bile.

Nor is the concept of a middle-aged peak in the prevalence of gall stones supported by any evidence. All the epidemiological studies have found that the prevalence increases steadily with age, so that men in their 80 s are more prone to the condition than women in their 40 s.

Finally, gall stones are very common in men and extremely common in women. The sex differential changes with advancing age: under 40 years the female to male ratio for gall stones is $3: 1$, whereas over 80 years the ratio is $3: 2$, and gall stones are much more frequent anyway.

The infamous five F's should be given a decent cremation, in the hope that the phoenix of a better understanding will arise from the ashes.

\footnotetext{
${ }^{1}$ Heaton KW. The epidemiology of gallstones and suggested aetiology. Clin Gastroenterol 1973;2:67-83.

${ }^{2}$ Langman MJS. The epidemiology of chronic digestive disease. London: Edward Arnold, 1980.

${ }^{3}$ Price WH. Gall-bladder dyspepsia. Br Med f 1963;ii :138-41.
}

\section{The BMA's conference season}

The thousand or so doctors who have taken part in the BMA's recent conference season have now returned to their surgeries, wards, laboratories, and lecture rooms. In such a diverse and knowledgeable profession as medicine to obtain a united professional view on any subject is an achievement- to do so on all would be an idealist's dream. But a surprising degree of agreement was achieved. The now-well-established pattern of five craft conferences ${ }^{12} 3$ followed by the Annual Representative Meeting ( $p$ 245) is probably as effective a system as can be devised to decide policies for the profession. The working relations between the individual autonomous crafts and the BMA-doctors' major professional organisation and their biggest trade union-have been better than some expected when the constitutional reforms of the 1970s were completed. ${ }^{4}$ Furthermore, minorities have seats and a hearing at the ARM. Important disagreements are inevitable, but at the ARM this year-guided by some skilful chairmanship from Dr E B Lewis in his final year in the chair-these were debated freely and usually without public rancour, and undoubtedly the Representative Body's opinion will be carefully considered by those crafts whose policy decisions may not have found wider professional support.

A case in point was the ARM's rejection of the concept of a permanent "third force"-community health doctors who would provide clinical services such as developmental paediatrics and health screening as a half-way home between general practice and hospital care (p 258)-after the Community
Medical Conference had strongly supported it. ${ }^{2}$ Community medicine doctors will no doubt accept the decision as a political reality and take another look at how to resolve this particular problem, bearing in mind, presumably, that the ARM asked the Central Committee for Community Medicine to continue "to negotiate a career structure for community health doctors as a matter of urgency and report back not later than the 1982 ARM." Another arena of dissension concerned events surrounding the Review Body's 1981 award, with the junior doctors strongly critical of the BMA's response. ${ }^{2}$ In the event the conflict was not debated as the Representative Body gave the juniors permission to withdraw the critical motion. Later, the HJSC chairman, Dr M L R Rees, promised that however strongly the juniors felt about an issue they would approach it constructively-though that did not mean, he added, that the Representative Body would be hearing less from the committee next year. It was 12 years ago after the Aberdeen ARM that many juniors left the BMA because it would not set up what in their view was the proper representative machinery for junior staff. New machinery was eventually constructed and has now been working satisfactorily for some time: it is encouraging that the juniors use it so vigorously-their craft conference was well attended and its debates of a high standard, while their contributions to ARM debates were excellent.

Several important subjects attracted overwhelming support. One was the future of the Review Body, with representatives 